\title{
Effect of Salt-water Fog on Fatigue Crack Nucleation of Al and Al-Li Alloys
}

\author{
Gamboni, O. C., Moreto, J. A.*, Bonazzi, L. H. C., Ruchert, C. O. F. T., Bose Filho, W. W. \\ Department of Materials Engineering, University of São Paulo - USP, \\ Av. Trabalhador São Carlense, 400, CEP 13566-590, São Carlos, SP, Brazil
}

Received: March 18, 2013; Revised: October 25, 2013

\begin{abstract}
Fatigue and corrosion-fatigue tests were performed to quantify the fatigue properties of AA2524-T3 and AA2198-T851 Al alloys. High cycle axial fatigue tests were carried out under air and salt-water fog conditions. In air, the specimens were fatigue tested at a frequency of $50 \mathrm{~Hz}$, using specimens with and without preconditioning in a salt spray chamber, and for the corrosion fatigue condition, the tests took place at a frequency of $30 \mathrm{~Hz}$ in a salt-water fog condition. In all cases it was used a sinusoidal waveform and a stress ratio $(\mathrm{R})$ of 0.1 . The results indicate that the saline environment had a deleterious effect on the fatigue life of the two aluminum alloys. AA2524-T3 exhibited a better fatigue strength than AA2198-T851 when fatigue tested in air. However, considering the corrosion fatigue test in a saline fog environment an inverse behavior was observed with the AA2198-T851 exhibiting higher fatigue strength.
\end{abstract}

Keywords: Al-Li alloys, AA2198-T851, AA2524-T3 corrosion fatigue, S-N curves, saline environment

\section{Introduction}

Aluminum alloys are produced in many forms, such as castings, sheets, plates, bars, rods and forgings, and used by different industrial sectors including the aircraft industry ${ }^{1}$. This late has been on constant search for improved materials that offer benefits in terms of performance, weight and cost savings. The advantages of these alloys are their light weight, corrosion resistance, and very high thermal and electrical conductivity. The aforementioned factors, added to the fact that some of these alloys can be formed in a soft condition and heat-treated to a temper comparable to that of structural steel, make them very attractive for aircraft parts. Aluminum alloys are materials that effectively reduce the weight of vehicles, and their applications are expanding continually.

The aircraft industry has recently shown renewed interest in the aluminum-lithium (Al-Li) alloys, which offers improvements in structural performance through density reduction, increased stiffness, better fracture toughness and higher fatigue crack growth resistance, as well as enhanced corrosion resistance. Since the discovery, in the mid-1950s, that adding lithium to aluminum alloys results in materials with high specific modulus (E/ $\rho)$, aluminum manufacturers have been diligent in their efforts to fabricate commercial alloys. The low ductility and fracture toughness of the first generation of the Al-Li alloys, as well as their strong anisotropy, kept the researchers in the search for improved Al-Li alloys ${ }^{2,3}$. The second generation was developed aiming weight saving by low density, however, it was also characterized by short-transverse fracture toughness, lower plane stress $\left(\mathrm{K}_{\mathrm{c}}\right)$ fracture toughness/residual strength in sheet and higher anisotropy of tensile properties ${ }^{4,5}$. This

*e-mail: jeferson_moreto@yahoo.com.br generation also presented higher damage tolerance due to pronounced slip reversibility and large crack path deviation when compared with that of conventional aluminum alloys. However, must be observed that those factors causing improvement in fatigue crack propagation resistance, very often tend to have a detrimental influence on fatigue crack initiation. Some of these Al-Li alloys, such as Al-Li-Zr and $\mathrm{Al}-\mathrm{Mg}-\mathrm{Li}-\mathrm{Zr}$ alloys are more resistant to stress corrosion cracking (SCC) than more conventional alloys subjected to the same heat treatments ${ }^{6}$.

The shortcomings of $2^{\text {nd }}$ generation of Al-Li alloys led to the development of Al-Li alloys with reduced $\mathrm{Li}$ concentration (from 0.75 to $1.8 \mathrm{wt}$ pct) named as 2195 , 2196, 2297, 2397, 2198, 2099, 2199, 2050, 2060, and C99N. This late generation, was designed with the understanding of the influence of chemical composition and microstructure on mechanical and corrosion performances. The well understanding of this late has becoming quite important since fatigue strength of aluminum alloys is lowered in aggressive medium, such as seawater, particularly when the high cycle fatigue regime is considered ${ }^{7}$.

The corrosion and fatigue properties of aluminum alloys are major issues in the service life assessment of aircraft structures and in the management of aging air fleets $^{8}$. Corrosion Fatigue (CF) phenomena is an important and complex failure mode that may take place in highperformance structural metals submitted to repeated loads in an aggressive environment. CF affects nuclear power systems, steam and gas turbines, aircrafts, marine structures, pipelines and bridges. Corrosion fatigue, which is defined as the sequential stages of metal damage, evolves accumulated cyclic loads in environments that are more aggressive than inert or benign environments. It is the result 
of the interaction of irreversible cyclic plastic deformation with localized chemical or electrochemical reactions. Environment-enhanced fatigue is a modern term; however, the term $\mathrm{CF}$ is traditionally used when referring specifically to electrochemical environments. Mechanical fatigue experiments and analyses described in recent textbooks ${ }^{9,10}$ provide the basis for understanding corrosion fatigue ${ }^{11}$.

2XXX series aluminum alloys are used for the construction of structural components due to their high toughness and good fatigue strength. These alloys generally have a desirable combination of strength, damage tolerance, formability and density that is suitable for many engineering applications. Alloys of the $2 \mathrm{XXX}$ series are especially sensitive to aqueous medium containing chloride ions, because such medium favor oxidation and pitting corrosion of these alloys, generating stress concentrators that reduce their fatigue life ${ }^{12,13}$.

The AA2198-T851 aluminum alloy was designed to exhibit good mechanical properties for use in aircraft structural components. Its chemical composition is based mainly on $\mathrm{Cu}$, with minor amounts of $\mathrm{Fe}, \mathrm{Si}, \mathrm{Mn}, \mathrm{Mg}, \mathrm{Cr}$, $\mathrm{Zn}, \mathrm{Zr}$, Li and $\mathrm{Ag}$. This alloy contains lithium as an alloying element to reduce its density and increase its Young's modulus, thereby saving weight. In fact, the addition of 1 wt $\%$ lithium to aluminum reduces the alloy's density by $3 \%$ and increases its elastic modulus by about $6 \%{ }^{[14]}$.

Owing to their high strength and low density, the Al-Cu-Mg based 2XXX series of aluminum alloys, such as the AA2524, are widely used for constitutive aircraft parts; hence, damage tolerance is a critical issue. This alloy was developed by the Aluminum Company of America (ALCOA) in the 1990s by adjusting the $\mathrm{Cu}$ and $\mathrm{Mg}$ alloying elements and reducing $\mathrm{Fe}$ and $\mathrm{Si}$ levels ${ }^{15}$. New generations of aluminum alloys, that includes the $3^{\text {rd }}$ generation of AlLi alloys, has being developed to improve their specific mechanical properties, through microstructure optimization, reduced anisotropy ( $\mathrm{Zr}$ and $\mathrm{Mn}$ additions) and thermomechanical processing ${ }^{5}$, looking for the substitution of conventional $\mathrm{Al}$ alloys. The literature contains several works that discuss the fatigue performance of the AA2524 alloy, which is well known to possess superior fracture toughness and fatigue crack propagation resistance.

The aim of this work was to evaluate the fatigue and corrosion fatigue resistance of the AA2198-T851 Al-Li alloy (from the $3^{\text {rd }}$ generation), comparing them with the AA2524-T3, considering the effect of a saline environment in the pre-corroded (conditioned for 15 days in a salt spray chamber) and salt-water fog conditions.

\section{Experimental Procedure}

\subsection{Material and specimens' configuration}

The materials used in this investigation were the AA2524-T3 (base alloy) produced by ALCOA and the AA2198-T851 (Al-Li alloy) produced by Rio Tinto Alcan, both provided as $1.6 \mathrm{~mm}$ sheets in the bare condition (without any cladding or other surface treatment). Table 1 lists the chemical composition of their major elements.

Tensile tests were carried out according to the ASTM E 8M standard ${ }^{16}$, using 05 specimens for each Al alloy,
Table 1. Chemical composition (wt \%) of the aluminum alloys.

\begin{tabular}{ccc}
\hline Elements & AA2524-T3 & AA2198-T851 \\
\hline $\mathrm{Cu}$ & 3.84 & 3.68 \\
$\mathrm{Li}$ & - & 1.01 \\
$\mathrm{Si}$ & 0.04 & 0.03 \\
$\mathrm{Fe}$ & 0.06 & 0.08 \\
$\mathrm{Mg}$ & 1.31 & 0.31 \\
$\mathrm{Mn}$ & 0.56 & - \\
$\mathrm{Ti}$ & 0.029 & 0.027 \\
$\mathrm{Zr}$ & - & 0.12 \\
$\mathrm{Zn}$ & 0.01 & 0.01 \\
$\mathrm{Cr}$ & - & - \\
$\mathrm{Al}$ & Balance & Balance \\
\hline
\end{tabular}

removed longitudinally to the sheet rolling direction, see Figure 1a.

The fatigue tests followed the ASTM E466 standard ${ }^{17}$, with load ratio $(\mathrm{R})$ of 0.1 , and specimen size and geometry as presented in Figure 1b. The fatigue specimens were removed from the sheet similarly to the tensile specimens. The Stress-Life (S-N) for each curves were obtained using a minimum of 04 specimen per stress level and when possible, 06 stress amplitude levels (180, 160, 130, 110, 90 and 60 $\mathrm{MPa})$, in the following conditions: air (base line); salt-water fog $(3.5 \mathrm{wt} \% \mathrm{NaCl})$ and using specimens preconditioned for 15 days inside of a salt spray chamber, in a salt-water fog $(5$ wt $\% \mathrm{NaCl}$ ) at $35^{\circ} \mathrm{C}$. The applied preconditioning condition is similar to that recommended for corrosion evaluation in salt spray condition by the ASTM B $117^{[18]}$. For the base line and preconditioned conditions, the S-N curves were obtained in air, using a sinusoidal waveform and $50 \mathrm{~Hz}$ frequency. Corrosion fatigue $(\mathrm{CF})$ tests were carried out using a sinusoidal waveform at $30 \mathrm{~Hz}$ frequency, inside of a small acrylic chamber where a constant flux of salt-water fog, generated through a special device developed by the authors, was maintained during testing.

This special acrylic chamber, developed for the CF tests is shown schematically in Figure 2. In this setup, the $3.5 \mathrm{wt} \% \mathrm{NaCl}$ fog passed through the chamber, supplied by the external reservoir and then expelled to the external environment. The salt solution in the reservoir had a constant $\mathrm{pH}$ of 7.2 and both were controlled during tests. All the tests were performed using a servo-hydraulic testing system with $100 \mathrm{kN}$ capacity.

\section{Results and Discussion}

From the tensile test results, Table 2, it was observed that the AA2198-T851 (Al-Li) alloy showed slightly higher tensile strength parameters than AA2524-T3, and the values obtained in this work compares quite well with the tensile results from Cavaliere et al. ${ }^{19}$ and Alexpoulos et al. ${ }^{20}$.

Figure 3 presents the fatigue life curves of the AA2524-T3 and AA2198-T851 aluminum alloys for the three conditions used here (air, pre-corroded and saltwater fog conditions). It is observed that in air, without the preconditioning, the AA2524-T3 alloy presented slightly better fatigue resistance than the AA2198-T851. 

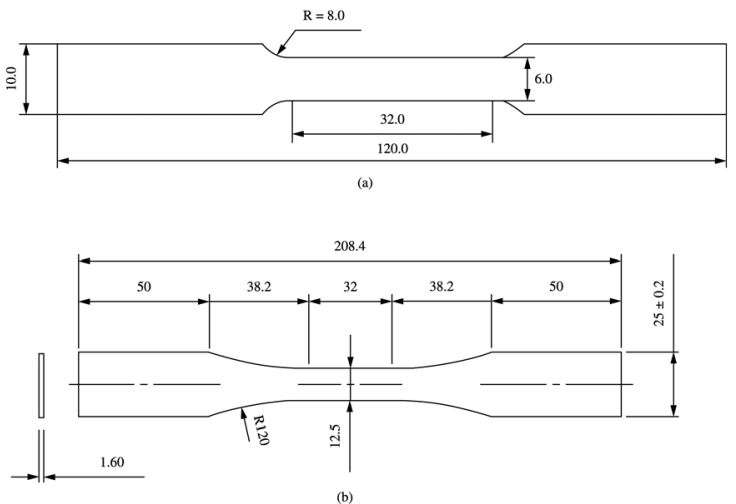

Figure 1. Size and geometry of the (a) tensile and (b) fatigue specimens. The dimensions are in $\mathrm{mm}$.

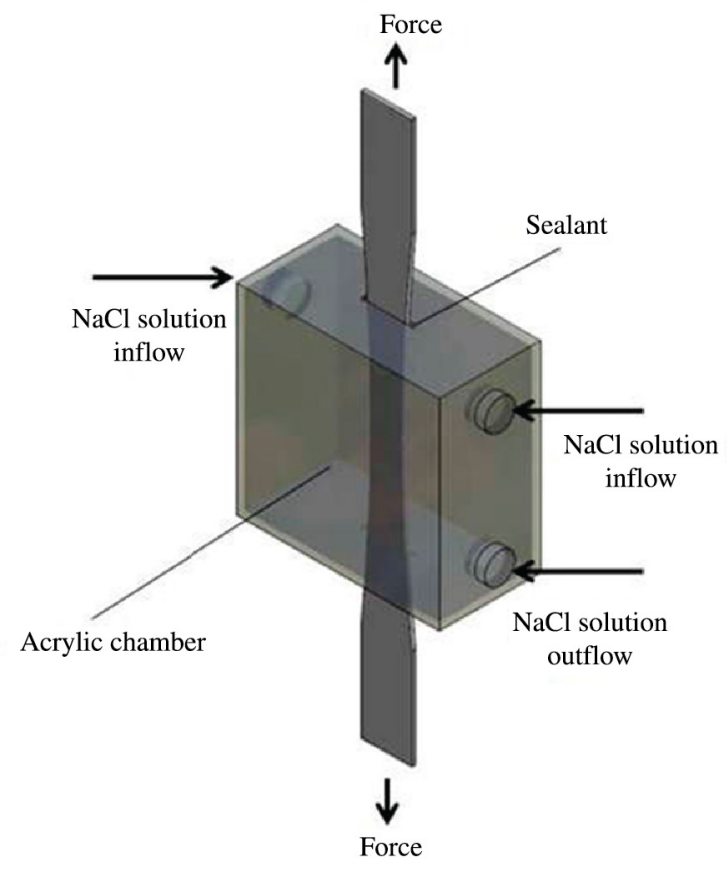

Figure 2. Schematic view of the experimental setup for corrosion fatigue tests.

Table 2. Tensile test results. The standard desviation is in brackets.

\begin{tabular}{cccc}
\hline Alloy & $\sigma_{\text {uts }}(\mathbf{M P a})$ & $\sigma_{\mathbf{y}}(\mathbf{M P a})$ & EL $(\%)$ \\
\hline AA 2198 T8 & $480(7.3)$ & $439(6.7)$ & $10.3(5.0)$ \\
AA 2524 T3 & $445(1.7)$ & $340(2.5)$ & $19.7(2.2)$ \\
\hline
\end{tabular}

The fracture surface analysis carried out by Gamboni and presented elsewhere ${ }^{21}$ has shown that all the crack nucleation sites were located at the specimens' surface. The surface is weaker than the interior metal in the same state, since at the surface the atoms do not have neighbors, and it is likely that the stress to cause plastic flow for these atoms is slightly lower than at interior. Also, at the surface, irregularities may be formed during specimen preparation

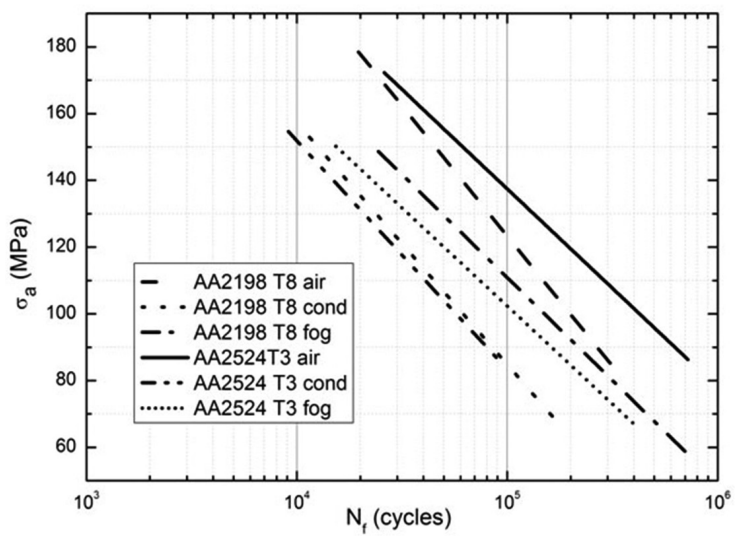

Figure 3. Comparison of S-N curves of AA2524-T3 and AA2198-T851 aluminum alloys in tested under different environments and specimens conditions.

introducing stress concentrators. In ductile metals, fatigue crack nucleation takes place by formation of permanent slip bands on the surface of the specimen, where intrusions (missing material below surface) and extrusions (projection of the material above surface) take place. Considering $\mathrm{HCF}$ regime, it has been observed a general trend, as higher is the material tensile strength longer is the fatigue life. However, comparing the tensile mechanical strength from both Al alloys (Table 2), the observed difference in the mechanical strength is not sufficient to cause improvement on the fatigue life of the AA2198-T851 Al alloy, or it may be overtaken by any other microstructural effect, such as precipitates size and distribution. Further investigation is on the way using transmission electron microscope to make a detailed characterization of the microstructure. Difference in roughness would be another possibility, however as verified by Gamboni ${ }^{21}$ the specimens from both alloys presented similar roughness.

It was observed that results from open literature are quite rare for AA2128-T581. The only work found in this temper condition was the work from Cavaliere et al. ${ }^{19}$, using specimens with different thickness $(5 \mathrm{~mm})$ and stress ratio $(\mathrm{R}=0.33)$ from the current work. To correctly compare the $\mathrm{S}-\mathrm{N}$ curves, it would be necessary to convert these data using the one of the rules proposed in the literature, as for example the Gerber's rule as applied by Alexopoulos et al. ${ }^{20}$. Comparing the results it is seen that in the present work it was obtained a S-N curve with slightly higher fatigue lives for the same stress amplitudes, for a life of $10^{5}$ cycles, in this work the correspondent stress amplitude was 125 $\mathrm{MPa}$ and in the work of Cavaliere et al. ${ }^{19}$, converted by Alexopoulos et al. ${ }^{20}$, it was $108 \mathrm{MPa}$. This small difference may be due to the application of the Gerber's equation, since the adjustment is quite dependent on the chosen conversion rule (could be SWT or Goodman equations).

Sodium chloride environment had a detrimental effect on the fatigue behavior of both $\mathrm{Al}$ alloys, independently of the fatigue test type. Overall, the significant reduction in the fatigue strength ( $\mathrm{S}-\mathrm{N}$ curves) of the two $\mathrm{Al}$ alloys obtained from the specimens previously exposed to the saline environment in the salt spray chamber before the 


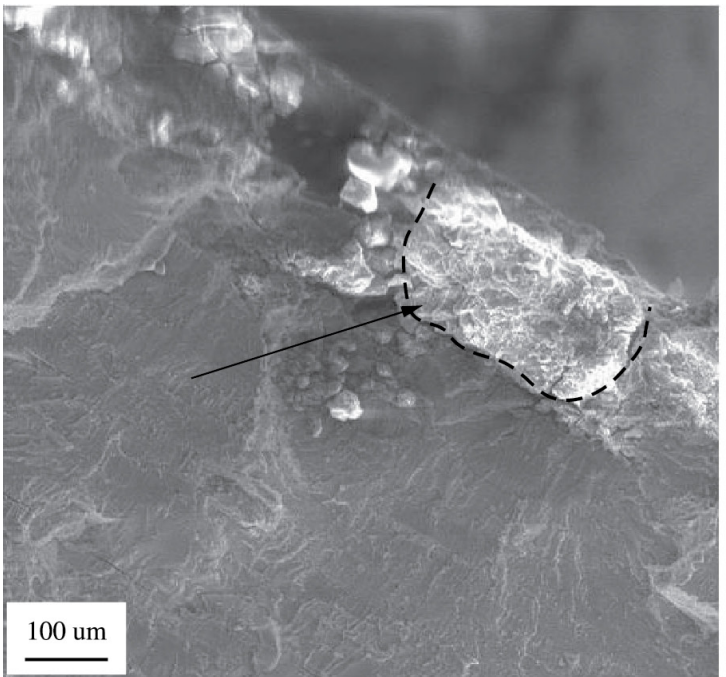

(a)

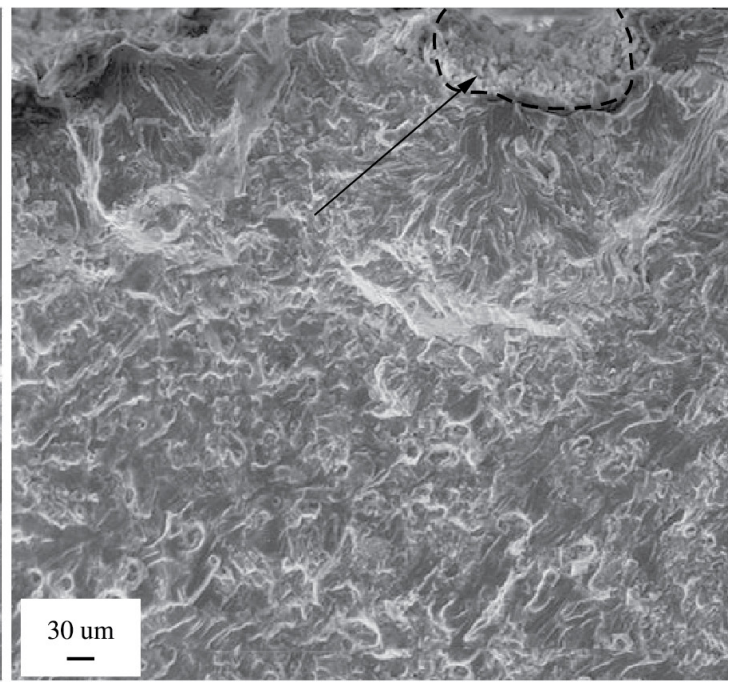

(b)

Figure 4. Fatigue crack nucleation sites from corrosion pits at the specimen surface (region marked with black arrows) (a) AA2524-T3 and (b) AA2198-T851, observed after conditioning and fatigue tests.

fatigue tests, can be attributed to pitting corrosion. It is seeing that the 15 days soaking time was long enough to cause formation of severe pits on the specimens surfaces, at a point that the fatigue resistance from the two alloys became quite similar (Figure 3), and very low when compared with the fatigue resistance curves obtained in air. The fracture surface analysis using SEM confirmed that, in the presence of corrosion pits, the fatigue cracks always initiated from any of these pits, see the examples in Figure 4. Pitting is a highly localized type of corrosion that occurs in the presence of aggressive chloride ions ${ }^{21}$. According to Lin and Yang ${ }^{13}$, corrosion pits on the surfaces of axially fatigued specimens may become stress concentration sites, thus enhancing the onset of corrosion and resulting in a short fatigue life. Pao et al. ${ }^{22}$ studied corrosion fatigue crack initiation in AA7075 and AA7050 aluminum alloys and found that corrosion pits can significantly speed up fatigue crack initiation.

It is also observe in Figure 3 that crack nucleation life was also affected when the aluminum alloys were exposed simultaneously to the saline environment and repeated loads, it is seen that the fatigue lives were shorter than that in air (without preconditioning). As mentioned before, during the tensile part of the loading cycle slip steps at the surface are produced. The extent of the surface slip offset can be diminished by reverse slip during unloading or subsequent compression loading in a fully reverse fatigue. The presence of a hostile environment aggravates both the effects of plasticity and surface degradation by adding chemical phenomena to the process, and when the slip steps form during the tensile portion of a fatigue cycle in a chemically aggressive medium, the chemisorptions of the embrittling species (such as oxygen or hydrogen) or the formation of an oxide layer on the freshly formed slip step, making reverse slip difficult on the same slip plane upon load reversal. Since Al alloys have a high affinity for oxygen, oxidation occurs rapidly on both sides of the extrusions, promoting the early formation of a $\operatorname{crack}^{9,23}$. Comparing both alloys when tested in a saline fog environment, it is observed that the AA2128-T851 presented a slight improved corrosion fatigue resistance. This fact may be linked to the corrosion results obtained by Moreto $^{24}$. This author has concluded that the AA2128-T851 exhibited a better corrosion resistance than AA2524-T3, therefore it is more resistance to oxidation in the presence of the saline fog during the corrosion fatigue tests, that the testing time was much shorter than the 15 days of the salt spray tests. The corrosion fatigue time did not allow the formation of severe pits on the specimens' surfaces as was the cases of the pre-corroded specimens.

\section{Conclusions}

An experimental investigation was made in two aluminum alloys used in aircraft fabrication.

A comparison of the $\mathrm{S}-\mathrm{N}$ curves revealed that in air the AA2524-T3 exhibited fatigue strength slightly better than the AA2198-T851 Al-Li alloy.

Considering the $\mathrm{S}-\mathrm{N}$ curves from the pre-corroded condition, it was observed that the sodium chloride environment had a significant effect on the fatigue behavior of both $\mathrm{Al}$ alloys, this was due to the severe conditions that the specimens were submitted in the salt spray chamber, with massive formation of pits on the specimens' surface that acted as stress concentrators and reduced very similarly the fatigue life in both alloys.

From the corrosion fatigue tests can be concluded that the better oxidation resistance in saline environment of the AA2198-T851 than the AA2524-T3, was responsible for the AA2198 T851 to present higher corrosion fatigue resistance.

\section{Acknowledgments}

The authors gratefully acknowledge the Department of Materials Engineering, University of São Paulo - USP for providing the laboratories facilities and the Brazilian research funding agencies $\mathrm{CNPq}$ and CAPES (Process: BEX4936/10-8) for their financial support. 


\section{References}

1. American Society for Metals - ASM. Metals Handbook. In: Davis JR. Properties and Selection: Nonferrous Alloys and Special - Purpose Materials. ASM International; 1990. v. 2, p. 17-22.

2. Sanders TH Jr and Starke EA Jr. Aluminum-Lithium Alloys. In: Proceedings of the 1st International Aluminum-Lithium Alloys; 1980; Stone Mountain. Warrendale: Metallurgical Society of AIME; 1981.

3. Sanders TH Jr and Starke EA Jr. Aluminum-Lithium Alloys 11. In: Proceedings of the 2nd International Conference on Aluminum-Lithium Alloys; 1983; Monterey. Monterey; 1983.

4. Giummarra C, Thomas B and Rioja RJ. New Aluminum Lithium alloys for aerospace applications. Proceedings of the Light Metals Technology Conference. 2007.

5. Rioja RJ and Liu J. The Evolution of Al-Li Base Products for Aerospace and Space Applications. Minerals, Metals \& Materials Society and ASM International. 2012.

6. Conde BJF and De Damborenea JJ. Characterization of the SCC behavior of 8090 Al-Li alloy by means of the slow-strainrate technique. Corrosion Science. 1995; 40(1):91-102. http:// dx.doi.org/10.1016/S0010-938X(97)00117-0

7. Devereux OF, McEvely AJ and Staehle RW. Corrosion Fatigue: Chemistry, Mechanic, and Microstructure, Part VII, Aluminum Alloys. Corrosion Engineering. 1972: 451.

8. Menan F and Henaff G. Influence of frequency and exposure to a saline solution on the corrosion fatigue crack growth behavior of the aluminum alloy 2024. International journal of fatigue. 2009; 31:1684-1695. http://dx.doi.org/10.1016/j. ijfatigue.2009.02.033

9. Suresh S. Fatigue of Materials. 2nd ed. Boston; Cambridge; 1998. p. 1-29. http://dx.doi.org/10.1017/CBO9780511806575.003

10. Dowling NE. Mechanical Behavior of Materials. Prentice Hall: Engineering Methods for Deformation Fracture and Fatigue; 1992.

11. Zhang R and Mahadevan S. Reliability-based reassessment of corrosion fatigue life. Structural Safety. 2001; 23:77-91. http:// dx.doi.org/10.1016/S0167-4730(01)00002-9

12. Hollingsworth E H and Hunsciker HY. Corrosion of aluminum and aluminum alloys. In: American Society for Metals - ASM.
Metal Handbook. 9th ed. Ohio: ASM International; 1987. p. 583-609.

13. Lin C-K and Yang S-T. Corrosion Fatigue Behavior of 7050 Aluminum Alloys in Different Tempers. Engineering Fracture Mechanics. 1998; 59(6):779-795. http://dx.doi.org/10.1016/ S0013-7944(97)00173-2

14. Warner T. Recently-Developed Aluminium Solutions for Aerospace Applications. Materials Science Forum. 2006; 519-521:1271-8. http://dx.doi.org/10.4028/www.scientific. net/MSF.519-521.1271

15. Zheng ZQ, Cai B, Zhai T and Li SC. The behavior of fatigue crack initiation and propagation in AA2524-T34 alloy. Materials Science and Engineering A. 2011; 528:2017-2022. http://dx.doi.org/10.1016/j.msea.2010.10.085

16. American Society for Testing and Materials - ASTM. E8/E8M09: Test methods for testing of metallic materials. ASTM; 2009.

17. American Society for Testing and Materials - ASTM. E466-07: Practice for conducting force controlled constant amplitude axial fatigue tests of metallic materials. ASTM; 2007.

18. American Society for Testing and Materials - ASTM. B117-11: Standard Practice for Operating Salt Spray (Fog) Apparatus. ASTM; 2011.

19. Cavaliere P, Cabibbo M, Panella F and Squillace A. 2198 Al-Li plates joined by friction stir welding: mechanical and microstructural behavior. Materials \& Design. 2009; 30:36223631. http://dx.doi.org/10.1016/j.matdes.2009.02.021

20. Alexopoulos ND, Migklis E, Stylianos A and Myriounis DP. Fatigue behavior of the aeronautical Al-Li (2198) aluminum alloy under constant amplitude loading. International Journal of Fatigue. 2013; 56:95-105. http://dx.doi.org/10.1016/j. ijfatigue.2013.07.009

21. Gamboni OC. Estudo do efeito do ambiente no comportamento em fadiga de novas ligas de AL de grau aeronáutico. [Dissertação]. São Carlos: Universidade de São Paulo; 2011.

22. Pao PS, Feng CR and Gill SJ. Corrosion fatigue crack initiation in aluminum alloys 7075 and 7050. Corrosion Science. 2000; 56(10):1022-1031. http://dx.doi.org/10.5006/1.3294379

23. Manson SS and Halford GR. Fatigue and Durability of Structural Materials. Ohio: ASM International; 2006.

24. Moreto JA. Estudo da corrosão e corrosão-fadiga em ligas de Al e Al - Li de Alta Resistência para Aplicação Aeronáutica. [Tese]. São Carlos: Universidade de São Paulo; 2012.

\section{List of symbols}

$\begin{array}{ll}\text { E } & \text { Young's modulus } \\ \text { R } & \text { Applied stress ratio } \\ \text { El } & \text { Total elongation } \\ \text { бa } & \text { Stress amplitude } \\ \sigma y & \text { Yield limit }\end{array}$

$\sigma \mathrm{m}$
UTS
CF
SEM
TEM

Mean stress

Ultimate tensile stress

Corrosion fatigue

Scanning Electronic Microscope

Transmission Electron Microscope 